\title{
Clinical Treatment of Deep Infiltrating Endometriosis - Impacts on Sexual Function
}

\author{
Lima Ryane Vieira ${ }^{1, *}$, Lopes Reginaldo Guedes Coelho" ${ }^{1}$, Pereira Ana Maria Gomes ${ }^{1}$, \\ Bray-Beraldo Fernando $^{2}$, Gazzo Cláudia ${ }^{1}$, David Simone Denise ${ }^{1}$, Martins João Alfredo ${ }^{1}$, \\ Pinto Fernando Campos Gomes ${ }^{3}$
}

\author{
${ }^{1}$ Department of Gynecology, Institute of Medical Assistance to the State Public Servant (IAMSPE), Sao Paulo, Brazil \\ ${ }^{2}$ Department of Surgery, IAMSPE, Sao Paulo, Brazil \\ ${ }^{3}$ Postgraduate Program in Health Sciences, IAMSPE, Sao Paulo, Brazil
}

Email address:

ryanevlm@gmail.com (L. R. Vieira)

${ }^{*}$ Corresponding author

\section{To cite this article:}

Lima Ryane Vieira, Lopes Reginaldo Guedes Coelho, Pereira Ana Maria Gomes, Bray-Beraldo Fernando, Gazzo Cláudia, David Simone Denise, Martins João Alfredo, Pinto Fernando Campos Gomes. Clinical Treatment of Deep Infiltrating Endometriosis - Impacts on Sexual Function. Clinical Medicine Research. Vol. 10, No. 3, 2021, pp. 67-72. doi: 10.11648/j.cmr.20211003.12

Received: April 11, 2021; Accepted: April 29, 2021; Published: May 14, 2021

\begin{abstract}
Objectives: Considering the prevalence of endometriosis in reproductive-age women and its negative impact on life quality, the authors of the present research intended to evaluate the impact of clinical treatment on the sexual function of patients with deep infiltrating endometriosis treated at the Endometriosis and Chronic Pelvic Pain Clinic of HSPE-FMO. Methods: A prospective and comparative observational study was conducted between May 2015 and July 2019 in which data from 43 patients with presumed deep endometriosis were analyzed, including age, parity, surgical and obstetric history and Female Sexual Function Index (FSFI questionnaire). Statistical analysis was performed using multiple regression in order to compare the variables. Results: The mean age of the women who were studied was 39.16 years; all patients were symptomatic and most had rectosigmoid endometriosis $(65,1 \%)$. The median FSFI total score before treatment was 25.06 , with $60,5 \%$ of the women classified as having a sexual dysfunction. There was a risk for sexual dysfunction to become permanent following clinical treatment when this dysfunction was established previously. The Poisson multiple regression showed that sexual dysfunction before treatment was associated with a lower FSFI total score after treatment and dysfunction before treatment had a direct correlation with final score smaller than 26.55. Considering the FSFI total scores before and after clinical treatment, there was no significant difference in the improvement rate between groups. Conclusions: Most patients did not show improvement in sexual function after clinical treatment.
\end{abstract}

Keywords: Endometriosis, Sexuality, Drug Therapy

\section{Introduction}

Endometriosis is characterized by the presence of functional tissue, similar to the endometrium, outside the uterine cavity, most commonly in the pelvic peritoneum and ovaries. It may present as infiltrating lesions of adjacent organs [1]. The combination of retrograde menstrual flow with genetic, hormonal, and immunological factors and the cellular response of the eutopic endometrium could explain the etiopathogenesis of the condition $[2,3]$

The prevalence of this disease is approximately 10 to $20 \%$ in reproductive-age women [4] and the clinical picture is quite variable. A quarter of these patients may be asymptomatic, up to $80 \%$ may have chronic pelvic pain and 30 to $50 \%$ may have infertility. In addition to distortion of the pelvic cavity by endometriosis foci, immune cells, prostaglandins, cytokines, and oxidative stress from the disease may explain the association with infertility, in addition to the contribution of mood and anxiety disorders to this condition [5]. Perimenstrual urinary or evacuation symptoms are occasional complaints, especially in the infiltrating form of the disease, in which $5 \mathrm{~mm}$ or more of the 
peritoneum is affected [6].

In addition to the symptoms described above, quality of life is usually severely impaired in patients with endometriosis $[7,8]$. Dyspareunia is associated with anxiety and sexual dysfunction in all areas [8,9]. It is well described that sexual experiences are reinforced in subsequent relationships; thus, negative experiences can perpetuate sexual dysfunction and cause suffering, distress or interpersonal difficulty, making women unable to participate in sexual intercourse as they would like [10-12].

Despite some subjectivity, sexual function can be assessed using questionnaires such as the Female Sexual Function Index (FSFI), which has been validated for Brazilian Portuguese [13, 14].

Nuclear magnetic resonance and ultrasound imaging with intestinal preparation may presume a diagnosis of deep infiltrating endometriosis, although the definitive diagnosis of the disease is histopathological [15].

Faced with a clinical condition compatible with endometriosis, treatment with hormonal contraceptives and nonsteroidal anti-inflammatory drugs is considered the firstline treatment $[3,16]$. Surgery is reserved for cases that do not respond satisfactorily to clinical treatment or present with some degree of organ involvement $[3,15,17,18]$.

The objective of this study was to evaluate female sexual function, using the FSFI, before and after clinical treatment of patients with a presumptive diagnosis of deep infiltrating endometriosis, through transvaginal ultrasound exams with intestinal preparation or magnetic resonance imaging, seen at the Endometriosis and Chronic Pelvic Pain outpatient clinic of Hospital do Servidor Público Estadual- Francisco Morato de Oliveira (HSPE-FMO) between May 2015 and June 2019.

\section{Methods}

A prospective and comparative observational study was conducted between May 2015 and June 2019, in which data were evaluated from 43 women treated at the Endometriosis and Chronic Pelvic Pain outpatient clinic of HSPE-FMO. They all had a presumed diagnosis of deep infiltrating endometriosis, made through a combination of the clinical picture and specialized exams. The study included women were sexually active, in menacme, and given a presumptive diagnosis of deep endometriosis by magnetic resonance imaging or transvaginal ultrasound with intestinal preparation. The noninclusion criteria were patients who did not have sex or were referred during treatment. The present study was approved by the Ethics Committee of HSPE-FMO and registered at the Brazil Platform (Plataforma Brasil) under CAAE protocol no. 36273214.9.0000.5463.

The patients were evaluated in two consultations over a minimum period of three months after agreeing to participate in the study by signing an informed consent form. In the first consultation, the patient answered the FSFI in the office to quantify the sexual aspects before endometriosis treatment.
In the second consultation, the same questionnaire was answered to quantify the sexual aspects during the instituted treatment. It was not possible to establish a fixed time between the two consultations given the high demand for the outpatient clinic.

Patients who became sexually inactive, who were treated with gonadotropin-releasing hormone $(\mathrm{GnRH})$ analogs, who did not return for consultations, or whose imaging results did not show lesions suspected of infiltration were excluded from the study.

Initially, data on age, parity, surgical history, and symptoms that could be associated with deep infiltrating endometriosis lesions were collected. The characteristics of these lesions were recorded in imaging exams (transvaginal ultrasound with intestinal preparation or magnetic resonance imaging) in terms of the affected compartment and size.

All patients were treated with continuous combined contraceptive or progestin alone to induce amenorrhea. The treatment was individualized and chose in the first consultation, respecting the particularities of each case. Each patient was instructed to keep up the treatment until the second consultation, when the questionnaire was reapplied.

The applied FSFI is a brief, specific, multidimensional scale adapted to the Portuguese language that has significant reliability and validity [13] and transforms subjective measures into objective, quantifiable, and analyzable data [14]. This questionnaire consists of 19 questions grouped into six domains: desire, arousal, vaginal lubrication, orgasm, sexual satisfaction, and pain or discomfort. All response options are scored between 0 and 5 . To calculate the total score, the scores of the questions of each domain were summed, and this sum was multiplied by the correction factor established by the questionnaire authors. The resulting scores of all the domains were summed. The final scores range from 2 to 36, higher scores indicating better sexual function [13]. Scores less than or equal to 26.55 indicate sexual dysfunction [19].

Statistical analysis was performed for descriptive and comparative analyses using multiple Poisson or logistic regression to correlate epidemiological and clinical data with the questionnaire scores. The nonparametric Wilcoxon test was used to compare the pre- and posttreatment scores because the samples were dependent and paired. The categorical variables are expressed as percentages. The numerical variables are expressed as the mean and standard deviation when they had a normal distribution or as the median and quartiles when they had a nonparametric distribution.

\section{Results}

A total of 121 women were recruited. Of these, 45 were not included, and 33 patients were excluded. Therefore, data from 43 women aged 26 to 51 years (mean of $39.16 \pm 5.66$ ) were analyzed (Figure 1). 


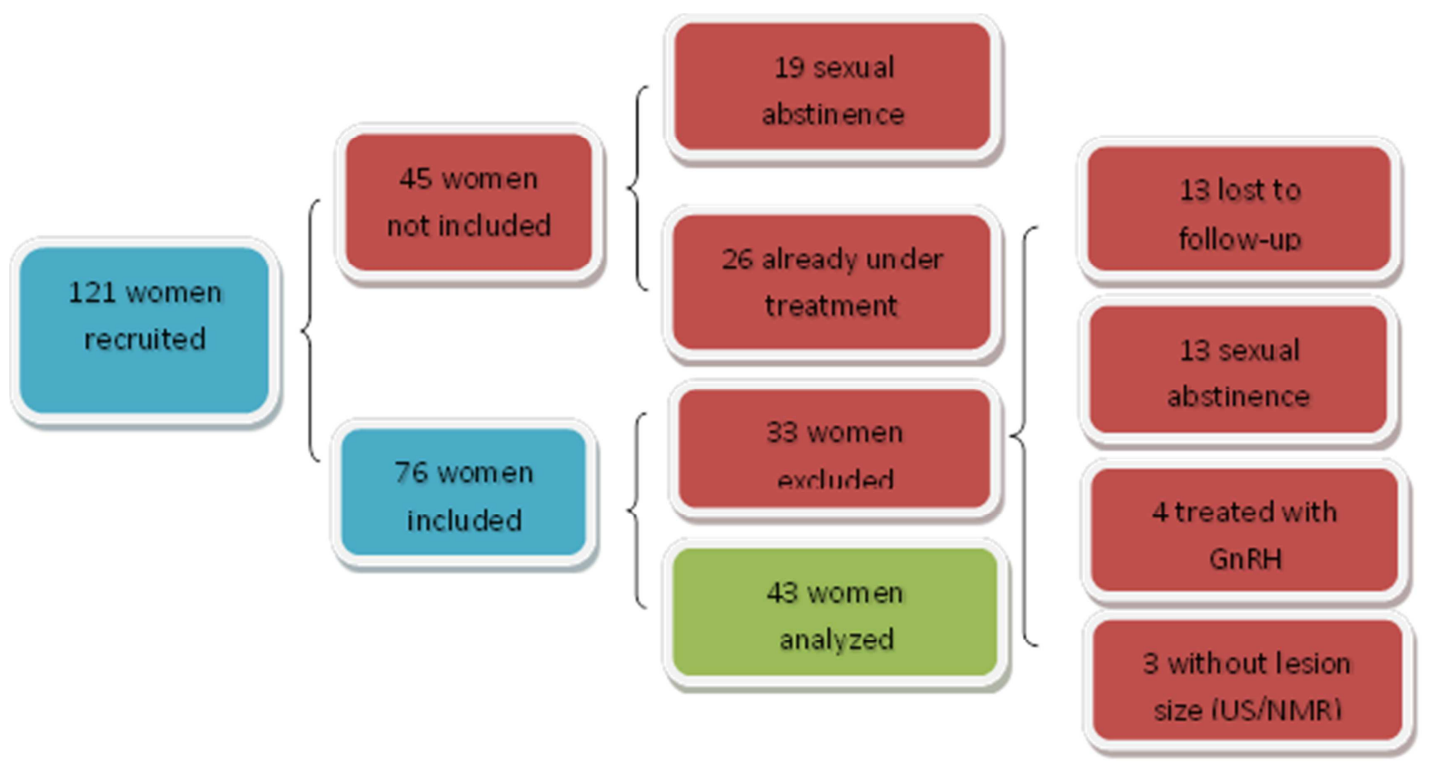

Figure 1. Flowchart of patient inclusion in the study.

\subsection{Population Characteristics}

Regarding obstetric history, 44.2\% (19) were nulliparous, and $55.8 \%$ (24) had one to three children. Normal delivery was the most prevalent mode of delivery, accounting for $62.8 \%$ (27) of births. Of the total, $14 \%$ (6) of the women had a history of miscarriage and $41.9 \%$ (18) of infertility. A history of pelvic gynecological surgery was observed in $14 \%$ (6) of the sample.

Regarding the clinical picture, all patients were symptomatic, with a mean symptom duration of 48 months (24-150), equivalent to approximately two years, and ranging from 1 to 360 months. The most prevalent symptoms were dysmenorrhea (95.3\%), dyspareunia (58.1\%), and acyclic pain $(60.5 \%)$. At HSPE-FMO, treatment for presumed deep endometriosis with combined oral contraceptive (20) or progestogen alone (23) was proposed.

Constipation was found $39.5 \%$ of the women, and the interval between bowel movements averaged 1.88 days, ranging from 1 to 3 days. Other, more specific pain symptoms were less reported, such as cyclic $(27.9 \%)$ and acyclic $(23.3 \%)$ dyschezia, cyclic $(9.3 \%)$ and acyclic $(11.6 \%)$ abdominal/intestinal pain, cyclic (11.6\%) and acyclic $(2.3 \%)$ hematochezia, and cyclic (7\%) and acyclic (4.7\%) urinary pain.

Regarding the location of the deep infiltrating endometriosis lesions described by ultrasound with intestinal preparation or magnetic resonance imaging, the most frequently affected region was the rectosigmoid (28), followed by the retrocervical region (15), vaginal fornices (5), rectovaginal septum (5), and bladder (2). Lesions suspected of cystic ovarian endometriosis concomitant with intestinal lesions were observed in $27.9 \%$ (12) of the cases and were bilateral in $25 \%$ (3).

Regarding the location, lesions in the vaginal fornix, vagina or rectovaginal septum accounted for $23.3 \%$ (10) of the cases; retrocervical, $34.9 \%$ (15); and intestinal, $65.1 \%$
(28). There was mention in 66 medical records of the size of the lesions, whose median size was $24 \mathrm{~mm}(18-32 \mathrm{~mm})$, ranging from 7 to $76 \mathrm{~mm}$.

Other characteristics related to the lesions, such as involvement of the intestinal muscle layer by the deep endometriosis lesion and percentage of the circumference of the intestinal loop affected by the lesion, were found in 29 and 25 records, respectively. Regarding infiltration, 58.1\% (25) affected the muscle layer of the wall of the affected intestinal loop, while $23.3 \%$ (10) also infiltrated the submucosal layer. The lesions affected up to $40 \%$ of the circumference of the intestinal loop.

\subsection{Main Results}

The questionnaires on sexual function were answered at a median interval of 16 months, ranging from 3 to 44 months. The mean FSFI total score before treatment was 25.06 $( \pm 0.96)$, and $60.5 \%$ (26) of the sample had a score smaller than 26.55. The mean score posttreatment score was 24.48 $( \pm 1.03)$, with no significant difference between the analyzed time periods.

Statistical analysis showed a parametric distribution for the FSFI total scores before and after treatment, but because they were dependent and paired samples, the Wilcoxon test was used to compare the scores. It was observed that the score improved in 23 women and worsened in 20 , with no significant difference. There was no significant difference in the improvement rate between groups $(\mathrm{p}>0.05)$.

Considering the cutoff point for sexual dysfunction, 3 $(6.97 \%)$ patients began to present dysfunction after treatment, 5 (11.63\%) no longer had sexual dysfunction after treatment, and $35(83.40 \%)$ did not change category, with no significant difference between groups $(\mathrm{p}>0.05)$.

The Poisson multiple regression showed that sexual dysfunction before treatment was associated with a lower FSFI total score after treatment, adjusted for age, rectosigmoid lesion and constipation after treatment (Table 1). 
Table 1. Poisson multiple regression analysis of the total posttreatment FSFI score.

\begin{tabular}{lllll}
\hline VARIABLE & Univariate analysis OR (CI) & p-value & Adjusted analysis OR (CI) & p-value \\
\hline Pretreatment dysfunction score & $-0,292(-0,414--0,170)$ & 0.000 & $0,796(0,695-0,911)$ & 0.001 \\
Age & $-0,012(-0,023--0,001)$ & 0.027 & $0,993(0,981-1,006)$ & 0.0327 \\
Rectosigmoid lesion & $-0,107(-0,233-0,018)$ & 0.090 & $0,937(0,819-1,072)$ & 0.347 \\
Constipation & $-0,205(-0,432-0,022)$ & 0.076 & $0,837(0,661-1,059)$ & 0.139 \\
\hline
\end{tabular}

OR: odds ratio

CI: confidence interval

When the variables associated with the categorical outcome of the FSFI after treatment were evaluated using multiple logistic regression, it was observed that dysfunction before treatment had a direct correlation with final score smaller than

26.55. These variable had a statistically significant and independent correlation after adjustment for age and acyclic pain after treatment (Table 2).

Table 2. Multiple logistic analysis of the categorical outcome of total FSFI score improvement after clinical treatment.

\begin{tabular}{llll}
\hline VARIABLE & Univariate analysis OR (CI) & p-value & Adjusted analysis OR (CI) \\
\hline Pretreatment dysfunction score & $19,6(4,02-95,45)$ & 0.000 & $16,666(2,77-100,18)$ \\
Age & $1,12(0,99-1,26)$ & 0.065 & $1,089(0,92-1,28)$ \\
Posttreatment Noncyclical pain & $3,82(0,83-17,58)$ & 0.085 & $1,102(0,14-8,93)$ \\
\hline
\end{tabular}

OR: odds ratio

CI: confidence interval

The isolated scores on each of the domains pre- and posttreatment were also compared using the Wilcoxon test, and no statistical significance was found in the analyses.

\section{Discussion}

The mean age found in this study corresponds to the age group in which endometriosis is typically diagnosed, the 4th decade of life [9, 19-21]. Regarding obstetric history, there was a high prevalence of primary or secondary infertility.

All patients were symptomatic because they were recruited from a pelvic pain outpatient clinic. Considering the median time since diagnosis and the time of treatment of these cases, a delay in diagnosis was observed. The delayed diagnosis can be explained by atypical clinical pictures, unavailability of complementary tests or lack of suspicion by physicians $[6,9$, 22].

Dysmenorrhea and deep dyspareunia, which were highly prevalent in this study, are the symptoms most commonly reported by patients with endometriosis [3, 7, 23, 24]. In the literature, the most common clinical presentation of these specific symptoms is cyclic [25], unlike in this study, where acyclic complaints were most common. This may be related to the memory of pain not obeying menstrual cyclicity, to dysmenorrhea topping all other pain complaints, or to the amenorrhea promoted by the treatment. Intestinal complaints, in turn, may signal intestinal involvement and require additional evaluation [17].

Regarding the negative impact of the symptoms on female sexual function, a prevalence of sexual dysfunction of $60.5 \%$ was observed in patients with a presumptive diagnosis of deep infiltrating endometriosis, a rate higher than that found by Fairbanks, Abdo, Baract \& Podgaec (2017) in the Brazilian population. In the present study, the permanence of sexual dysfunction after clinical treatment of suspected cases of infiltrating endometriosis was observed when this dysfunction was already established, in line with the study by Andres, Mendes, Hermandes, Araújo \& Podgaec (2019), but contrasting with that by Vercellini et al. (2018).

In the case of chronic pelvic pain in general, this painful symptom may persist even after treatment because it is also the result of central mechanisms, without the need for peripheral input [26]. Thus, older patients experience pain for a longer time [27], so they having lower FSFI scores. Data in the literature about age are conflicting [26].

The patients with low FSFI scores after treatment and suspicious lesions in the rectosigmoid were potential candidates for surgery $[28,29]$. It is worth mentioning that the absence of a definitive diagnosis of endometriosis and the exclusion of other diseases that may affect the patients' symptoms constitute a limitation of the study. The lack of data on the partner's condition is a limitation of the assessment made by the FSFI, as is the lack of family and sociocultural factors, sexual practices, and psychological condition, which are determinants of sexual choices and behaviors. Psychological status substantially affects sexual aspects $[5,7,26]$ and could explain, if evaluated, relevant aspects of the lives of patients who presented sexual dysfunction after treatment.

\section{Conclusions}

Most patients did not show improvement in sexual function after clinical treatment and that is a risk for sexual dysfunction to become permanent following clinical treatment when this dysfunction was established previously. These patients are potential candidates for the surgery approach, since it is well established that it is considered in women with persistent pain despite medical therapy

The authors of the present research suggest the conduction 
of future studies with interventional and randomized designs in order to consider others aspects that may affect the sexual response and the pain control of patients.

\section{Funding Statement}

The authors declare that they do not have any competing financial, professional or personal interests from other parties.

\section{Acknowledgements}

Authors are thankful to respondents of survey. The time they spared for this study have enable most of findings in this paper.

\section{References}

[1] Abrão M. S., Petraglia F., Falcone T., Keckstein, J., Osuga, Y. \& Chapron, C. (2015). Deep endometriosis infiltrating the recto-sigmoid: critical factors to consider before management. Human Reproduction Update, 21 (3), 329-339. https://doi.org/10.1093/humupd/dmv003.

[2] Kennedy S., Bergqvist A., Chapron C., D'Hoogde T., Dulseman G., Greb R., Hummelshoj L., Prentice A. \& Saridogan E. (2005). ESHRE guideline for the diagnosis and treatment of endometriosis. Human reproduction, 20 (10), 2698-2704. https://doi.org/10.1093/humrep/dei135

[3] Marian S. \& Hermanowicz-Szamatowicz K. (2020). Endometriosis - a decade later - still an enigmatic disease. What is the new in the diagnosis and treatment? Gynecological Endocrinology, $36 \quad$ (2), 104-108. https://doi.org/10.1080/09513590.2019.1675045

[4] Shafrir A. L., Farland L. V., Shah D. K., Harris H. R., Kvaskoff M., Zondevan K. \& Missmer S. A. (2018). Risk for and consequences of endometriosis: A critical epidemiologic review. Best Practice \& research. Clinical Obstetetrics \& Gynaecology, 51, 1-15. https://doi.org/10.1016/j.bpobgyn.2018.06.001

[5] Viganò P., Ottolina J., Bartiromo L., Bonavina G., Schimberni M., Villanacci R. \& Candiani M.(2020). Cellular Components Contributing to Fibrosis in Endometriosis: A Literature Review. Journal of Minimaly Invasive Gynecology, 27 (2), 287-295. https://doi.org/10.1016/j.jmig.2019.11.011

[6] Cozzolino M., Coccia M. E., Lazzeri G., Basile F. \& Troiano G.. (2019). Variables Associated with Endometriosis-related Pain: A Pilot Study using a Visual Analogue Scale. Revista Brasileira de Ginecologia e Obstetrícia, 41(3), 170-175. https://doi.org/10.1055/s-0039-1679879

[7] Shum L. K., Bedaiwy M. A., Allaire C., Williams C., Noga H., Albert A., Lisonkova S. \& Yong P. J. (2018). Deep dyspareunia and sexual quality of life in women with endometriosis. Sexual Medicine, 6 (3), 224-233. https://doi.org/10.1016/j.esxm.2018.04.006

[8] Yela D. A., Quagliato I. P. \& Benetti-Pinto C. L. (2020). Quality of Life in Women with Deep Endometriosis: A Cross-Sectional Study. Revista Brasileira de Ginecologia e Obstetrícia, 42 (2), 90-95. https://doi.org/10.1055/s-0040-1708091
[9] Lima R. V., Pereira A. M. G., Bray-Beraldo F., Gazzo C., Martins J. A. \& Lopes R. G. C. (2018). Female Sexual Function in women with suspected deep infiltrating endometriosis. Revista Brasileira de Ginecologia e Obstetrícia, 40(3), 115-120. https://doi.org/10.1055/s-00381639593

[10] Da Luz R. A., De Deus J. M., Valadares A. L. R. \& Conde D. M. (2018). Evaluation of sexual function in Brazilian women with and without chronic pelvic pain. Journal of Pain Reserach, 11, 2761-2767. https://doi.org/10.2147/JPR.S176851

[11] Fairbanks F., Abdo C. H., Baracat E. C. \& Podgaec S. (2017). Endometriosis doubles the risk of sexual dysfunction: a crosssectional study in a large amount of patients. Gynecological $\begin{array}{llll}\text { Endocrinology, } & 33 & \text { (7), } & 544-547 .\end{array}$ https://doi.org/10.1080/09513590.2017.1302421

[12] Kossel A., Cambridge S. B., Wagner U. \& Bonhoeffer T. (2001). A caged Ab reveals an immediate/instructive effect of BDNF during hippocampal synaptic potentiation. Proceedings of the National Academy of Sciences of the United States of, 98(23), 14702-14707. https://doi.org/10.1073/pnas.251326998

[13] Leite A. P. L., Moura E. A., Campos A. A. S., Mattar R., Souza E. \& Camano L. (2007). Validation of the Female Sexual Function Index in Brazilians pregnants. Revista Brasileira de Ginecologia e Obstetrícia, 29(8), 396-401. https://doi.org/10.1590/S0100-72032007000800003

[14] Rosen R. C., Brown C., Heiman J., Leiblum S., Meston C., Shabsigh R., Ferguson D. \& D’Agostinho Jr R. (2000). The Female Sexual Function Index (FSFI): a multidimensinal selfreport Instrument for the assessment of female sexual function. Journal of Sex \&Marital Therapy, 26 (2), 191-208. https://doi.org/10.1080/009262300278597

[15] Andres M. P., Mendes R. F. P., Hernandes C., Araújo S. E. A. \& Podgaec S. (2019). Hormone treatment as first line therapy is safe and relieves pelvic pain in women with bowel endometriosis. Einstein, 17, article eAO4583. Doi: 10.31.744/Einstein.journal/2019AO4583.

[16] Hickey M., Ballard K. \& Farquhar C. (2014). Endometriosis. $B M J, 348$, g1752. https://doi.org/10.1136/bmj.g1752

[17] Bray-Beraldo F., Pereira A. M. G., Gazzo C., Santos M. P. \& Lopes R. G. C. (2018). Surgical Treatment of Intestinal Endometriosis: Outcomes of Three Different Techniques. Revista Brasileira de Ginecologia e Obstetrícia, 40 (7), 390396. https://doi.org/10.1055/s-0038-1660827

[18] Vercellini P, Frattaruolo MP, Rosati R, Dridi D., Roberto A., Mosconi P., De Giorgi O., Cribiù F. M. \& Somigliana E. (2018). Medical Treatment or surgery for colorectal endometriosis? Results of a shared decision-making approach. Human Reprodution, $33 \quad$ (2), 202-211. https://doi.org/10.1093/humrep/dex364

[19] Wiegel M., Meston C. \& Rosen R. (2005). The Female Sexual Function Index (FSFI): cross-validation and development of clinical cutoff scores. Journal of Sex \& Marital Therapy, 31(1), 1-20. https://doi.org/10.1080/00926230590475206

[20] Bellelis P., Jr Dias J. A., Podgaec S., Gonzales M., Baracat E. C. \& Abraão M. S. (2010). Aspectos epidemiológicos e clínicos da endometriose pélvica - uma série de casos. Revista da Associação Médica Brasileira, 56 (4), 467-471. https://doi.org/10.1590/S0104-42302010000400022 
[21] Zarbo C., Brugnera A., Compare A., Secomandi R., Candeloro I., Malandrino C., Betto E., Trezzi G., Rabboni M., Bondi E. \& Frigerio L. (2019). Negative metacognitive beliefs predict sexual distress over and above pain in women with endometriosis. Archiches of Women's mental health, 22(5), 575-582. https://doi.org/10.1007/s00737-018-0928-9

[22] Medeiros L. R., Rosa M. I., Silva B. R., Reis M. E., Simon C. S., Dondossola E. R. \& Filho J. S. C. (2015). Accuracy of magnetic resonance in deeply infiltrating endometriosis: a systematic review and meta-analysis. Archives of Gynecology $\begin{array}{llll}\text { and } & \text { Obstetric, } & 291 & \text { (3), }\end{array}$ https://doi.org/10.1007/s00404-014-3470-7

[23] Cozzolino M., Magro-Malosso E. R., Tofani L \& Coccia M. E. (2018). Evaluation of sexual function in women with deep infiltrating endometriosis. Sexual \& Reproductive Healthcare, 16, 6-9. https://doi.org/10.1016/j.srhc.2017.12.005

[24] Sampson J. A. (1927). Metastatic or Embolic Endometriosis, due to the Menstrual Dissemination of Endometrial Tissue into the Venous Circulation. The American Journal of Pathology, 3 (2), 93-110.43.

[25] Zondervan K. T., Phil D., Becker C. M. \& Missmer S. A. (2020). Endometriosis. The New England Journal of Medicine, 382, 1244-1256. DOI: 10.1056/NEJMra1810764
[26] Lara L. A. S., Rosa e Silva A. C. J. S., Romão A. P. M. S. \& Junqueira F. R. R. (2008). The assessment and management of female sexual dysfunction. Revista Brasielira de Ginecologia e Obstetrícia, 30, 312-321. https://doi.org/10.1590/S010072032008000600008 .

[27] Mendonça C. R., Silva T. M., Arruda J. T., Garcia-Zapata, M. T. A. \& Amaral, W. N. (2012). Função sexual feminina: aspectos normais e patológicos, prevalência no Brasil, diagnóstico e tratamento. Femina, 40, 195-202.

[28] Alkatout I., Mettler L., Beteta C., Hedderich J., Jonat W., Schollmeyer T \& Salmassi A. (2013). Combined surgical and hormone therapy for endometriosis is the most effective treatment: prospective, randomized, controlled trial. Journal of Minimaly Invasive Gynecology, 20,473-481. https://doi.org/10.1016/j.jmig.2013.01.019

[29] Dunselman G. A., Vermeulen N., Becker C., Calhaz-Jorge C., D'Hooghe T., De Bie B., Heikinheimo O., Horne A. W., Kiesel L., Nap A., Prentice A., Saridogan E., Soriano D., Nelen W. (2014). ESHRE guideline: management of women with endometriosis. Human Reprodution, 29(3), 400-412. https://doi.org/10.1093/humrep/det457 